\title{
PENGARUH MINUMAN JAHE MERAH (ZINGIBER OFFCINALE ROSCOE VAR. RUBRUM) TERHADAP PENURUNAN SKALA NYERI DISMENOREA PRIMER PADA MAHASISWI DI PROGRAM STUDI S1 FARMASI UNIVERSITAS IMELDA MEDAN
}

\author{
Hartika Samgryce Siagian ${ }^{1}$, Mariyana Ritonga ${ }^{2}$ \\ Universitas Imelda Medan
}

\section{Article Info \\ Article history: \\ Received Aug 26, 2021 \\ Revised Sep 24, 2021 \\ Accepted Sep 27, 2021}

\section{Keywords:}

Dysmenorrhoea

Painful Menstruation Red Ginger

\begin{abstract}
Dysmenorrhoea is a gynecological complaint caused by an imbalance of the progesterone hormone in the blood, which causes pain and is most often characterized by menstrual cramps. A safe way to treat dysmenorrhoea is by boiling helbal, which is red ginger drink. The purpose of this study was to determine the effect of red ginger drink on reducing the scale of dysmenorrhoea pain on Pharmacy students at the University of Imelda Medan.This research method uses quantitative research with a descriptive design. The number of respondents in this study were 42 people using the sampling technique with the Slovin formula. The instrument used was a questionnaire with yes or no answer choices. The results of the study of 42 respondents, the majority who experienced pain or dysmenorrhoea, were 32 respondents with a percentage (92.9\%). And the effect of red ginger drink on the dysmenorrhoea pain scale was 29 respondents with a percentage $(69.0 \%)$. The effect of red ginger drink on the primary dysmenorrhoea pain scale is sufficient.
\end{abstract}

This is an open access article under the CC BY-SAlicense.

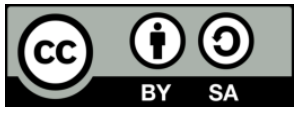

\section{Corresponding Author:}

Hartika Samgryce Siagian,

Program Studi S1 Farmasi,

Universitas Imelda Medan,

Jl. Bilal No. 52 Kelurahan Pulo Brayan Darat I Kecamatan Medan Timur, Medan - Sumatera Utara.

Email: hartikasiagian@gmail.com

\section{INTRODUCTION}

Nyeri menstruasi atau dismenorea ialah keluhan ginekologi yang diakibatkan karena ketidak seimbangan hormon progesterone yang berada dalam darah sehingga mengakibatkan timbulnya rasa nyeri dan yang paling sering terjadi pada perempuan. Perempuam yang mengalami nyeri menstruasi biasanya memproduksi prostaglandin 10 kali lebih banyak dibandingkan dengan perempuan yang tidak mengalami nyeri menstruasi. Angka kejadian nyeri menstruasi diseluruh dunia masih sangat banyak, persentasi kejadian nyeri menstruasi di dunia rata-rata lebih dari $50 \%$ atau berkisar sebesar 15,8-89,5\% wanita disetiap Negara mengalami nyeri menstruasi (Widiatami dkk, 2018). Dismenorea terbagi menjadi tiga jenis diantaranya dismenorea berat, dimenorea sedang dan dismenorea ringan. 
Dismenorea merupakan permasalahan yang banyak dikeluhkan oleh mahasiwa. Dismenora tidak membahayakan tetapi mengganggu aktivitas. Hal ini sesuai dengan penelitian Beddu (2015) yang menyatakan bahwa dampak dari dismenorea dapat mengganggu aktivitas mahasiswi dan menyebabkan ketidakhadiran di kampus (Beddu, 2015). Gangguan yang dirasakan oleh mahasiswa seperti pusing, nyeri perut hingga menyebabkan keringat dingin hingga pingsan.

ismenorea atau nyeri haid jika tidak segera diatasi akan mempengaruhi fungsi mental dan fisik penderita sehingga dibutuhkan tindakan secara farmakologis dan non farmakologis. Terapi farmakologi adalah tindakan pemberian obat-obatan analgesik untuk meredakan rasa nyeri yang ditimbulkan oleh dismenorea, sedangkan terapi non farmakologis adalah Tindakan pemberian minuman herbal dan relaksasi (Kusumastuti, 2017). Hal ini sesuai dengan Buku Pintar Menstruasi (Laila, 2011), ada beberapa cara untuk meringankan nyeri dismemorea antara lain: mengompres, relaksasi, istirahat, mengkonsumsi obat hingga mengkonsumsi minuman herbal.

Jahe merah merupakan salah satu minuman herbal yang dapat mengatasi nyeri saat menstruasi sebagai anti inflamasi dengan cara kerjanya yaitu dapat menghambat kerja enzim di dalam siklus cyclooxygenase sehingga dapat menghambat pelepasan enzim tersebut menuju prostaglandin yang menyebabkan inflamasi (Pratiwi, 2017).

Berdasarkan uraian diatas, peneliti ingin melakukan penelitian analisis skala nyeri pada mahasiswi Program Studi Farmasi di Universitas Imelda Medan yang menggunakan jahe merah pada saat dismenorea.

\section{RESEARCH METHOD}

Penelitian ini menggunakan metode analisis kuantitatif dengan desain deskriptif. Penelitian ini dilakukan di Universitas Imelda Medan, Jl. Bilal No. 24 Pulo Brayan Darat 1, Kota Medan yang dilaksanakan mulai dari bulan Januari-Juli 2020. Populasi yang digunakan dalam penelitian ini adalah mahasiswi Program Studi Farmasi di Universitas Imelda Medan prodi S1 farmasi yang mengalami menstruasi tingkat 1-4 berjumlah 71 orang mahasiswi. Sampel penelitian ini berjumlah 42 orang dengan menggunakan teknik pengambilan sampel dengan rumus Slovin. Pengolahan data pada penelitian ini meliputi Editing, Coding, Sortir, Entry Data dan Cleaning Data. Analisis dalam penelitian ini di olah dengan bantuan aplikasi pengolah data SPSS (Statistical product and service solution) 21.0 for windows.

\section{RESULTS AND ANALYSIS}

Karakteristik Responden Mahasiswi Universitas Imelda Medan Berdasarkan Usia

Tabel 1. Karakteristik Responden Mahasiswi Berdasarkan Usia

\begin{tabular}{ccc}
\hline Usia & Frekuensi & Persentase $(\%)$ \\
\hline 18 & 7 & 16,7 \\
\hline 19 & 10 & 23,8 \\
\hline 20 & 10 & 23,8 \\
\hline 21 & 4 & 9,5 \\
\hline 22 & 5 & 11,9 \\
\hline 23 & 2 & 4,8 \\
\hline 24 & 1 & 2,4 \\
\hline 25 & 1 & 2,4 \\
\hline 27 & 2 & 4,8 \\
\hline Total & $\mathbf{4 2}$ & $\mathbf{1 0 0}$
\end{tabular}

Berdasarkan tabel usia pada mahasiswi S1 farmasi yang mengalami dismenorea di Universitas Imelda Medan, bahwah jumlah persentase usia responden adalah 18 tahun sebanyak 7 $(16,7 \%)$ mahasiswi, usia 19 tahun sebanyak $10(23,8 \%)$, mahasiswi, usia 20 tahun sebanyak 10 $(23,8 \%)$ mahasiswi, usia 21 sebanyak $4(9,5 \%)$ mahasiswi, usia 22 tahun sebanyak $5(11,9 \%)$ mahasiswi, usia 23 tahun sebanyak $2(4,8 \%)$ mahasiswi, usia 24 sebanyak $1(2,4 \%)$ mahasiswi, usia 25 sebanyak $1(2,4 \%)$ mahasiswi, usia 27 tahun sebanyak $2(4,8 \%)$ mahasiswi dan memiliki usia dengan rata-rata 20,45 tahun dan usia termuda adalah 18 tahun serta usia tertua adalah 27 tahun. 
Tabel 2. Tabel Distribusi Frekuensi Responden Penelitian Berdasarkan Tingkat Prodi S-1

Farmasi

\begin{tabular}{ccc}
\hline Tingkat & Frekuensi & Persentase (\%) \\
\hline I & 19 & 45,2 \\
\hline II & 6 & 14,3 \\
\hline III & 8 & 19,0 \\
\hline IV & 9 & 21,4 \\
\hline Total & $\mathbf{4 2}$ & $\mathbf{1 0 0}$
\end{tabular}

Berdasarkan tabel 2 mahasiswi yang mengalami dismenorea pada setiap tingkat prodi S-1 Farmasi yaitu tingkat I sebanyak $19(45,2 \%)$ mahasiswi, tingkat II sebanyak $6(14,3 \%)$ mahasiswi, tingkat III sebanyak $8(19,0 \%)$ mahasiswi, tingakat IV sebanyak $9(21,4 \%)$ mahasiswi.

Tabel 3. Tabel Distribusi Kuesioner

\begin{tabular}{ccccc}
\hline Pertanyaan & \multicolumn{2}{c}{ Jumlah } & \multicolumn{2}{c}{ Persentase (\%) } \\
\hline & Ya & Tidak & Ya & Tidak \\
\hline X1 & 41 & 1 & 97,6 & 2,4 \\
\hline X3 & 39 & 3 & 92,9 & 7,1 \\
\hline X4 & 41 & 1 & 97,6 & 2,4 \\
\hline X5 & 19 & 23 & 45,2 & 54,8 \\
\hline X6 & 36 & 6 & 85,7 & 14,3 \\
\hline X7 & 42 & 0 & 100,0 & 0 \\
\hline X8 & 8 & 34 & 19,0 & 81,0 \\
\hline X9 & 34 & 8 & 81,0 & 19,0 \\
\hline X10 & 26 & 16 & 38,1 & 61,9 \\
\hline X11 & 32 & 10 & 76,2 & 23,8 \\
\hline X12 & 35 & 7 & 83,3 & 16,7 \\
\hline X13 & 34 & 8 & 83,3 & 16,7 \\
\hline X14 & 14 & 28 & 81,0 & 19,0 \\
\hline X15 & 36 & 6 & 85,3 & 66,7 \\
\hline X16 & 29 & 13 & 69,0 & 14,3 \\
\hline X17 & 27 & 27 & 64,3 & 64,3 \\
\hline X18 & 13 & 29 & 31,0 & 69,0 \\
\hline X19 & 7 & 35 & 16,7 & 83,3 \\
\hline X20 & 17 & 25 & 40,5 & 49,5 \\
\hline Jumlah & $\mathbf{5 6 5}$ & $\mathbf{2 8 7}$ & $\mathbf{1 . 3 2 1 , 4}$ & $\mathbf{6 9 7 , 2}$ \\
\hline
\end{tabular}

Berdasarkan tabel distibusi kuesioner responden yang paling banyak mengetahui atau menjawab di dalam kuesioner bagian X6 atau kuesioner di bagian nomor enam yaitu: apakah usia mahasiswi waktu mengalami dismenorea berbeda-beda sebanyak 42 responden menjawab ya dengan persentasi $(100 \%)$ dan berdasarkan tabel distribusi kuesioner yang terkecil didalam kuesioner bagian X19 yaitu: apakah anda meminum jahe merah lebih dari satu kali dalam sehari sebanyak 7 responden dengan persentasi $(16,7 \%)$.

\subsection{Pembahasan}

\section{Nyeri Haid atau Dismenorea}

Nyeri haid merupakan gangguan fisik yang sangat menonjol pada wanita yang sedang mengalami menstruasi berupa gangguan nyeri atau kram pada perut yang terjadi selama haid. Yang memiliki dampak yang cukup besar pada mahasiswi karena menyebabkan terganggunya aktivitas sehari-hari (Putri, dkk, 2017). Berdasarkan penelitian ini mahasiswi S1 Farmasi Universitas Imelda Medan yang mengalami nyeri haid sebanyak 39 mahasiswi dengan persentasi (92,9\%) data. Dampak dismenorea yang dialami mahasiswi mempengaruhi terganggunya aktivitas sebanyak 34 mahasiswi dengan persentasi $(81,0 \%)$. Penelitian ini menunjukkan bahwa nyeri dismenorea pada mahasiswi sangat mempengaruhi aktivitas sehari-hari.

Sebagian nyeri dengan menggangu aktivitas sehari hari, respon analgetik untuk menghilangkan rasa sakit minimal, dan adanya keluhan mual, pusing dan sebagainya. Untuk mengatasi nyeri haid ini dapat digunakan obat anti inflamasi untuk mengurangi gejala yang 
ditimbulkan (Larasati dan Alatas, 2016). Berdasarkan penelitian ini mahasiswi universitas Imelda Medan yang mengalami nyeri haid berlebihan atau berat sebanyak 19 mahasiswi dengan persentasi $(45,2 \%)$.

\section{Pengaruh Minuman Jahe Merah Terhadap Penurunan Nyeri}

Jahe merah merupakan salah satu rempah wangi yang khas. Dalam keseharian, jahe merah sering dimanfaatkan untuk menunjang kesehatan manusia. Di Indonesia jahe merah dapat tumbuh hampir diseluruh wilayah. Budi daya tanaman herbal jahe merah banyak ditemukan di pulau Jawa, Sumatera, Kalimantan, dan beberapa pulau lainnya (Zulpan, dkk, 2019).

Jahe merah dipercaya dapat mengatasi rasa nyeri saat mestruasi, karena jahe merah ini bersifat menghangatkan tubuh, anti inflamasi dan analgesik yang dapat menghambat kerja enzim dalam siklus siklooksigenase sehingga dapat menghambat pelepasan enzim tersebut menuju prostaglandin yang menyebabkan terjadinya inflamasi. Selain itu jahe merah juga dapat menghambat terjadinya kontraksi pada uterus yang dapat menyebabkan nyeri saat menstruasi (Larasati dan Alatas, 2016). Berdasarkan penelitian ini mahasiswi Universitas Imelda Medan yang mengetahui adanya pengaruh minuman jahe merah terhadap penurunan skala nyeri dismenorea sebanyak 17 mahasiswi dengan persentasi (40,5\%). Penelitian ini menunjukkan bahwa pengetahuan tentang pengaruh minuman jahe merah terhadap mahasiswi Universitas Imelda Medan masih dibawah $50 \%$.

\section{CONCLUSION}

Berdasarkan hasil penelitian yang telah dilakukan di Universitas Imelda Medan tentang pengaruh minuman jahe merah terhadap penurunan nyeri dismenorea maka dapat disimpulkan sebagai berikut:

- Dari hasil penelitian ini menunjukkan bahwa nyeri haid dapat mengganggu aktivitas mahasiswi Universitas Imelda Medan sesuai dengan data penelitian dari 34 mahasiswi dengan persentasi $(81,0 \%)$ tergaggu aktivitasnya. Penelitian ini menunjukkan bahwa nyeri dismenorea atau haid pada mahasiswi sangat mempengaruhi aktivitas.

- Berdasarkan hasil penelitian ini bahwa minuman jahe merah dapat mengurangi rasa nyeri haid atau nyeri dismenorea sesuai dengan persentase penelitian sebanyak 29 mahasiswi dengan persentase $(69,0 \%)$. Penelitian ini menunjukkan bahwa minuman jahe merah sangat berpengaruh terhadap penurunan nyeri haid atau dismenorea.

\section{REFERENCES}

Beddu, S., Mukarramah, S., Lestahulu, V. 2015. Hubungan status gizi Dan usia menarche dengan dismenore primer Pada remaja putri.The southeast Asian journal Of midwifery Hal. 16.

Citrawathi, D., M. 2014. Sistem reproduksi manusia. Yogyakarta. Ghara ilmu. Hal 6, 7, 8.

Dieny, F., F. 2014. Permasalahan gizi Pada remaja putri. Graha ilmu. Hal. $80,81,82,83,84,85,86,87,88$.

Kusumastuti, D., A. dan Hartina, D. 2017. Pengaruh pemberian jahe merah terhadap perubahan nyeri disminore. Jurnal the $5^{\mathrm{TH}}$ urecol proceeding. Hal 758.

Laila, N.N. 2011. Buku Pintar Menstruasi. Jogjakarta: Buku Biru.

Larasati, T., dan Alatas, F. 2016. Dismenore primer dan faktor risiko dismenore primer pada remaja. Jurnal Majority. Hal 79, 80.

Pundati, M,. T. Sistiarani, C., Hariadi, B. 2016. Faktor-faktor Yang berhubungan Dengan kejadian dismenore Pada mahasiswa semester VIII Universitas Jenderal suedirman University. Jurnal kesmas Indonesia. Hal.41.

Pujiana, D., Haryani, D., Rini, P., S. 2019. Efektifitas konsumsi air rebusan jahe merah terhadaf intensitas disminorea primer Pada mahasiswi. Masker medika. Hal 299.

Pratiwi, L., A. dan Mutiara, H. 2017. Pengaruh jahe terhadap nyeri saat menstruasi. Jurnal Majority, Volume 6, Nomor 1. Hal 51, 54.

Proverawati, A. SKM., MPH. Misaroh, S., Skep. Ns. 2009. Menarche menstruasi pertama penuh makna. Nuha medika. Hal 83, 84, 85, 86, 87. 
P, T., L. 2015. Manfaat jahe merah (Zingiber officianale Roscoe) terhadap kadar asam urat. Jurnal agromed unila. Hal 533, 534.

Putri, S., A. Yunus, M., Fanani, E. 2017. Hubungan antara nyeri haid (disminorea) terhadap aktivitas belajar pada siswi kelas XI SMA Negeri 52 Jakarta. Jurnal elektronik. Hal 1.

Rahayu, K., D. Nujulah, L. 2018. Efektivitas pemberian ekstrak jahe terhadap intensitas dismenore Pada mahasiswi akademi kebidanan sakinah pasuruan. Embrio, jurnal kebidanan. Hal 69.

Rahayu, A., Pertiwi, S., Patimah, S. 2017. Pengaruh endorphine massage terhadap rasa sakit dismenore Pada mahasiswi jurusan kebidanan poltekes kemenkes Tasikmalaya tahun 2017. Midwife journal. Hal 25.

Rahayu, R., Patimah, S., Rosmatin, E. 2019. Pengaruh minuman jahe merah terhadap penurunan skala nyeri disminorea primer pada siswi kelas VIII Di SMPN 10 Tasikmalaya tahun 2018. Jurnal midwife journal. Hal 27.

Rustam, E. 2014. Gambaran pengetahuan remaja putri terhadap nyeri haid (disminorea) dan cara penanggulangannya. Jurnal kesehatan andalas. Hal 287.

Saryono. (2011). Metologi Penelitian Kesehatan. Jakarta : Mitra Cendekia.

Widiatami, T., W. Melyani, N., Admini. 2018. Study literaturetentang pemberian minuman kunyit asam terhadap tingkat nyeri menstruasi Pada remaja putri. Jurnal kebidanan. Hal. 139-140.

Zulpan, I., Mulyani, H., S. dan Yudhapramesti, P. 2019. Pelatihan kewirausahaan melalui budidaya jahe merah bagi warga Di kecamatan Jatinagor, Kabupaten Sumedang, Jawa Barat. Jurnal pengabdian kepada masyarakat. 